\title{
Chromatin Structures of the Rat Tyrosine Aminotransferase Gene Relate to the Function of Its cis-Acting Elements
}

\author{
DORIS NITSCH, A. FRANCIS STEWART, MICHAEL BOSHART, RUBEN MESTRIL, $\dagger$ \\ FALK WEIH, AND GÜNTHER SCHÜTZ* \\ Institute of Cell and Tumor Biology, German Cancer Research Center, Im Neuenheimer Feld 280, \\ D-6900 Heidelberg, Federal Republic of Germany
}

Received 27 December 1989/Accepted 28 March 1990

\begin{abstract}
The relationship between DNase I-hypersensitive sites (HSs) and transcriptional enhancers of the rat tyrosine aminotransferase (TAT) gene was examined by comparing HSs in and around the TAT gene with the activity of the corresponding DNA sequences in transient transfection assays. In this manner, we identified two HSs as liver-specific enhancers. Of three hepatoma cell lines examined, only one sustained TAT mRNA levels comparable to those of liver. In this cell line, both enhancers were strongly active, and strong hypersensitivity in chromatin over the enhancers was evident. The other two hepatoma cell lines had reduced levels of TAT mRNA and no or altered hypersensitivity over either the enhancers or the promoter. One of these lines carried a negative regulator of the TAT gene, the tissue specific extinguisher Tse-1. This cell line exhibited all HSs characteristic of the strongly active gene except at the promoter; however, one enhancer was inactive even though hypersensitive in chromatin. In a TAT-nonexpressing cell line, inactivity of both enhancers correlated with absence of the respective HSs. We conclude that although hypersensitivity in chromatin necessarily accompanies cell-type-specific enhancer activity, the occurrence of cell-type-specific HSs does not imply that the underlying sequences harbor enhancers active in transient transfection assays.
\end{abstract}

The association of DNA and protein in the nucleus of eucaryotic cells is referred to as chromatin. The bulk of chromatin is nucleosomal; however, short nucleosomefree regions are detectable by an enhanced rate of cleavage with DNase I and are termed DNase I-hypersensitive sites (DNase I HSs). HSs correlate with regions where cisregulatory elements lie, and it is believed that the hypersensitivity to nucleases reflects accessibility to regulatory proteins (see references 11 and 25 for reviews). Thus, the mapping of HSs surrounding a gene offers a means to locate potential cis-regulatory elements. For example, extensive analysis of chromatin features in the chicken lysozyme gene domain in expressing and nonexpressing tissues and cell lines has elucidated the sequences that control cell-specific and hormone-responsive expression of this gene (summarized in reference 15 ).

Recent advances in the understanding of regulated gene expression in higher eucaryotes have highlighted the fact that cis-regulatory elements are frequently located at relatively large distances from the promoter. Studies of the mammalian albumin gene have demonstrated that high-level, tissue-specific expression is a property of the promoter region $(20,30,38)$. However, appropriate expression of albumin gene constructs in transgenic mice requires an element located 10 kilo base pairs (kb) upstream (39). Similarly, elements located $50 \mathrm{~kb} 5^{\prime}$ to the $\beta$-globin gene convey position-independent and copy-number-dependent expression in transgenic mice (26). In both cases, the upstream elements were initially identified as DNase I HSs (13, $39,48)$.

To investigate the control of rat tyrosine aminotransferase (TAT) gene expression, we determined the occurrence of

* Corresponding author.

$\dagger$ Present address: Department of Medicine, Division of Endocrinology and Metabolism, University of California-San Diego Medical Center, San Diego, CA 92103-9981.
HSs in TAT gene chromatin in expressing and nonexpressing cells and designed transfection experiments based on the location of these sites. The TAT gene is subject to several levels of gene regulation. It is preferentially expressed in parenchymal cells of the adult liver (28). Gene activity increases dramatically a few hours after birth (24). TAT transcription can be stimulated by glucocorticoid hormones $(23,42)$ and by glucagon, which acts via the cyclic AMP (cAMP) pathway $(29,42 ; \mathrm{F}$. Weih et al., submitted for publication). Both stimuli may be involved in the developmental activation of the gene (40). In addition, analysis of hepatoma-fibroblast cell hybrids (43) identified a negative regulator of the TAT gene, termed tissue-specific extinguisher 1 (Tse-1; 32). The locus for Tse-1 has been mapped to the distal part of human chromosome $17 \mathrm{q}$ (34).

Previously, glucocorticoid-dependent chromatin changes $2.5 \mathrm{~kb}$ upstream of the transcription start site (2) led to the definition of the functional glucocorticoid response element of the TAT gene (31). Here we identify two HSs that lie further upstream and function as liver-specific enhancers. By comparing HSs and the enhancing activities of the corresponding sequences in different cell lines, we are able to relate the functional relevance of different chromatin features to the transcriptional activity of the gene.

\section{MATERIALS AND METHODS}

Plasmids. Isolation of rat TAT 5'-flanking sequences to approximately $-18.7 \mathrm{~kb}$ from an EMBL3 rat liver library (44) led to the construction of pTC18.7 and pTC5.9 from pTC3.0 (pTATCAT in reference 31). These plasmids were used to construct a $5^{\prime}$ deletion series in which the following restriction sites were used (positions are given in base pairs upstream of the transcription start site): StuI (approximately -18000), PvuI (-11116), XbaI (-9232), PvuII (-4289), and KpnI (-351). Internal deletion constructs were derived from pTC18.7 by deletion of an XhoI (-3918)-HindIII (-3341) fragment in pTC18.7 $\Delta-3.6 \mathrm{HS}$ and a PvuI (-11116)-SfiI 
$(-8449)$ fragment in pTC18.7 $-11 \mathrm{HS}$. The double-deletion construct pTC18.7 $\Delta-11 /-3.6 \mathrm{HS}$ combines deletion of the XhoI-HindIII fragment with deletion of a PvuI (-11116)ScaI (-9382) fragment. pTC11.1 $1-3.6 \mathrm{HS}$ and pTC9.2 $\Delta-$ $3.6 \mathrm{HS}$ were cloned by exchange of the BssHII (-4881)BamHI (-1300) fragment between the respective 5 ' deletion plasmid and pTC18.7A-3.6HS. pTC-11HS, pTC-5.4HS, and pTC-3.6HS have the following fragments inserted into pTC0.35: PvuI (-11116)-ScaI (-9382), ApaI (-6081)-XhoI (-3918), and XmnI (-3981)-HindIII (-3341), respectively. For chromatin analysis, single-copy TAT fragments were cloned into pBluescribe or pBluescript (Stratagene). In experiments depicted in Fig. 2 to 5 , the following subclones were used: pXA600 (XbaI [-9208]-ApaI [-8591]), EB670 (EcoO109 [-1974]-BamHI [-1300]), and SH800 (SauI $[+700]-H i n d I I I[+1500])$. Cloning of all plasmids was performed according to standard procedures (1). All plasmids were grown in an Escherichia coli dam dcm strain (GM119), and purification involved alkaline lysis and two successive $\mathrm{CsCl}$ gradient steps.

Cell culture and transfection. All cells were cultured in 1:1 (vol/vol) Dulbecco modified Eagle medium-Ham F12 medium supplemented with $10 \%$ fetal calf serum, $100 \mathrm{U}$ of penicillin per $\mathrm{ml}, 100 \mu \mathrm{g}$ of streptomycin per $\mathrm{ml}, 10 \mathrm{mM}$ $N$ - 2 - hydroxyethylpiperazine - $N^{\prime}$ - 2 -ethanesulfonic acid (HEPES; $\mathrm{pH} 7.4$ ), and $2 \mathrm{mM}$ glutamine. The medium for 7AD-7 and 7AE-27 cells (34) also contained $800 \mu \mathrm{g}$ of G418 per ml. Transient transfections were performed by lipofection (12). Cells were plated onto 6-cm-diameter dishes 1 day before transfection $\left(4 \times 10^{6} 7 \mathrm{AD}-7\right.$ and 7AE-27, $10^{6} \mathrm{HTC}$, and $\left.5 \times 10^{5} \mathrm{XC}\right)$. Both DNA and lipid (30 $\mu \mathrm{g}$ of Lipofectin; Bethesda Research Laboratories, Inc.) were diluted separately in $500 \mu$ l of HBS buffer ( $20 \mathrm{mM}$ HEPES [pH 7.4], 150 $\mathrm{mM} \mathrm{NaCl}$ ), mixed, and left for 10 to $15 \mathrm{~min}$ at room temperature. The cells were washed twice with serum-free medium and then incubated for 3 to $4 \mathrm{~h}$ at $37^{\circ} \mathrm{C}$ with the lipid-DNA mix. Then $2 \mathrm{ml}$ of serum-free medium was added, and incubation continued for 12 to $16 \mathrm{~h}$. A further change of serum-free medium followed, and cells were harvested after an additional 40 to $48 \mathrm{~h}$. $0.175 \mathrm{pmol}$ of each construct was made to a total of $2.7 \mu \mathrm{g}$ with carrier DNA (plasmid pUC). Transfection efficiency was controlled by cotransfection of an internal reference plasmid $(0.04 \mathrm{pmol}$ of pRSVlucAH [kindly provided by A. Hecht], which is the luciferase gene under control of the Rous sarcoma virus promoter [9]).

CAT and luciferase assays. Cells were washed twice with phosphate-buffered saline and harvested in $1 \mathrm{ml}$ of $150 \mathrm{mM}$ $\mathrm{NaCl}-40 \mathrm{mM}$ Tris chloride (pH 7.4)-1 mM EDTA. Extracts were prepared by three cycles of freezing and thawing of cells, 20 min of centrifugation at $4^{\circ} \mathrm{C}$, and suspension in 150 $\mu$ l of $250 \mathrm{mM}$ Tris chloride (pH 7.8)-1 mM EDTA-1 mM dithiothreitol. Protein concentration was determined by the method of Bradford (4). Chloramphenicol acetyl transferase (CAT) assays (19) were performed with $2 \mathrm{mM}$ acetyl coenzyme $\mathrm{A}$ and $1.25 \mu \mathrm{Ci}$ of $\left[{ }^{14} \mathrm{C}\right]$ chloramphenicol per $\mathrm{ml}$ in 0.25 $M$ Tris (pH 7.8)-5 mM EDTA. Heat treatment $\left(10 \mathrm{~min}, 60^{\circ} \mathrm{C}\right.$ ) of the extract was included before the assay to inactivate the deacetylase activity (7). The assay was quantified by liquid scintillation counting of the excised reaction products. The luciferase assay was performed as described elsewhere (9).

HS mapping. Preparation of nuclei from different glucocorticoid-induced $\left(10^{-6} \mathrm{M}\right.$ dexamethasone) tissues and cells, DNase I digestions, and indirect end-labeling analyses were performed as described elsewhere $(2,31)$.

RNA analyses. RNA preparation and Northern (RNA) analysis were done as described elsewhere $(5,10)$. The
RNase protection assay was performed as described previously (31), hybridizing $100 \mu \mathrm{g}$ of total RNA with $10 \mathrm{fmol}$ of a uniformly labeled SP6 transcript (35). RNA was prepared from cells transfected as described above and harvested after $30 \mathrm{~h}$ in serum-free medium. Transfection efficiency was controlled by performing luciferase assays.

\section{RESULTS}

Six HSs correlate to high basal level of transcriptional activity. We performed DNase I HS analysis in liver and kidney as well as in three hepatoma cell lines, 7AD-7, 7AE-27, and HTC, and the fibrosarcoma line XC (46). The basal level of TAT gene expression in these tissues and cell lines was determined by Northern blot analysis (Fig. 1C). TAT mRNA levels are high in liver and the hepatoma line 7AD-7, low in HTC and 7AE-27 cells, and undetectable in kidney and the fibrosarcoma line XC. 7AD-7 and 7AE-27 are microcell hybrids of a hepatoma line derived from H4IIEC3 that retain part of the long arm of human fibroblast chromosome $17(33,34)$. Several genetic markers from this chromosomal fragment are present in both 7AD-7 and 7AE-27 cells; however, the $T$ se-1 locus is contained only in 7AE-27 cells. As previously described (32), the presence of Tse-1 resulted in a dramatic reduction of TAT mRNA levels (Fig. 1C, lanes 7AD-7 and 7AE-27). This result is a consequence of reduced transcriptional activity of the gene, as assessed by nuclear run-on experiments (data not shown). We also compared the parental cell line H4IIEC3 and its derivative FTO-2B (32) with 7AD-7 cells and found comparable TAT mRNA level s and identical chromatin structures (data not shown). The hepatoma line HTC (47), which originates from a different tumor do than H4IIEC3-derived cell lines, showed 5- to 10-fold-reduced levels of TAT mRNA compared with liver and 7AD-7 cells (Fig. 1C).

Chromatin analysis was performed by isolating nuclei from these tissues and cell lines and treating them with increasing amounts of DNase I. Fifteen end-labeling strategies were used to cover the entire gene and up to $20 \mathrm{~kb}$ of $5^{\prime}$ and $10 \mathrm{~kb}$ of 3 '-flanking sequences. The analysis led to the identification of $11 \mathrm{HSs}$ in addition to those reported previously (2) (Fig. 1A and B). Each HS is named according to its approximate position relative to the transcription start site. These HSs fall into three categories. Two were present in all tissues and cell lines $(-18 \mathrm{HS}$ and $+12 \mathrm{HS})$. Three did not correlate to transcriptional activity or inactivity $(-16 \mathrm{HS}$, $+4.5 \mathrm{HS}$, and $+9 \mathrm{HS})$. The remaining HSs lay between $-11 \mathrm{~kb}$ and the start site of transcription and showed cell type distributions suggestive of a relationship to the transcriptional activity of the TAT gene. The functional relevance of the glucocorticoid-dependent $\mathrm{HS}$ at $-2.5 \mathrm{~kb}$ has been discussed previously (31). All cells in this study were treated with glucocorticoids before chromatin analysis to assess whether this site could form. The $-2.5 \mathrm{HS}$ was the only glucocorticoid-induced chromatin change observable throughout the $40 \mathrm{~kb}$ examined. We present the most interesting chromatin features in Fig. 2 to 5.

In Fig. 2, HSs visible from -16 to $-2 \mathrm{~kb}$ are compared in kidney, liver, 7AD-7, and XC nuclei. Kidney nuclei showed one prominent $\mathrm{HS}$ in this region $(-8 \mathrm{HS})$. This $\mathrm{HS}$ was not present in any other case examined. Liver and 7AD-7 nuclei displayed the same array of HSs in this region except that liver had an additional $\mathrm{HS}$ at $-7 \mathrm{~kb}$. XC cells showed only the $-16 \mathrm{HS}$ (see also Fig. 3 and 4). Thus, we have identified four HSs (-11HS, $-5.4 \mathrm{HS},-4.5 \mathrm{HS}$, and $-3.6 \mathrm{HS})$ in addition to the previously identified $-1.0 \mathrm{HS},-2.5 \mathrm{HS}$, and 


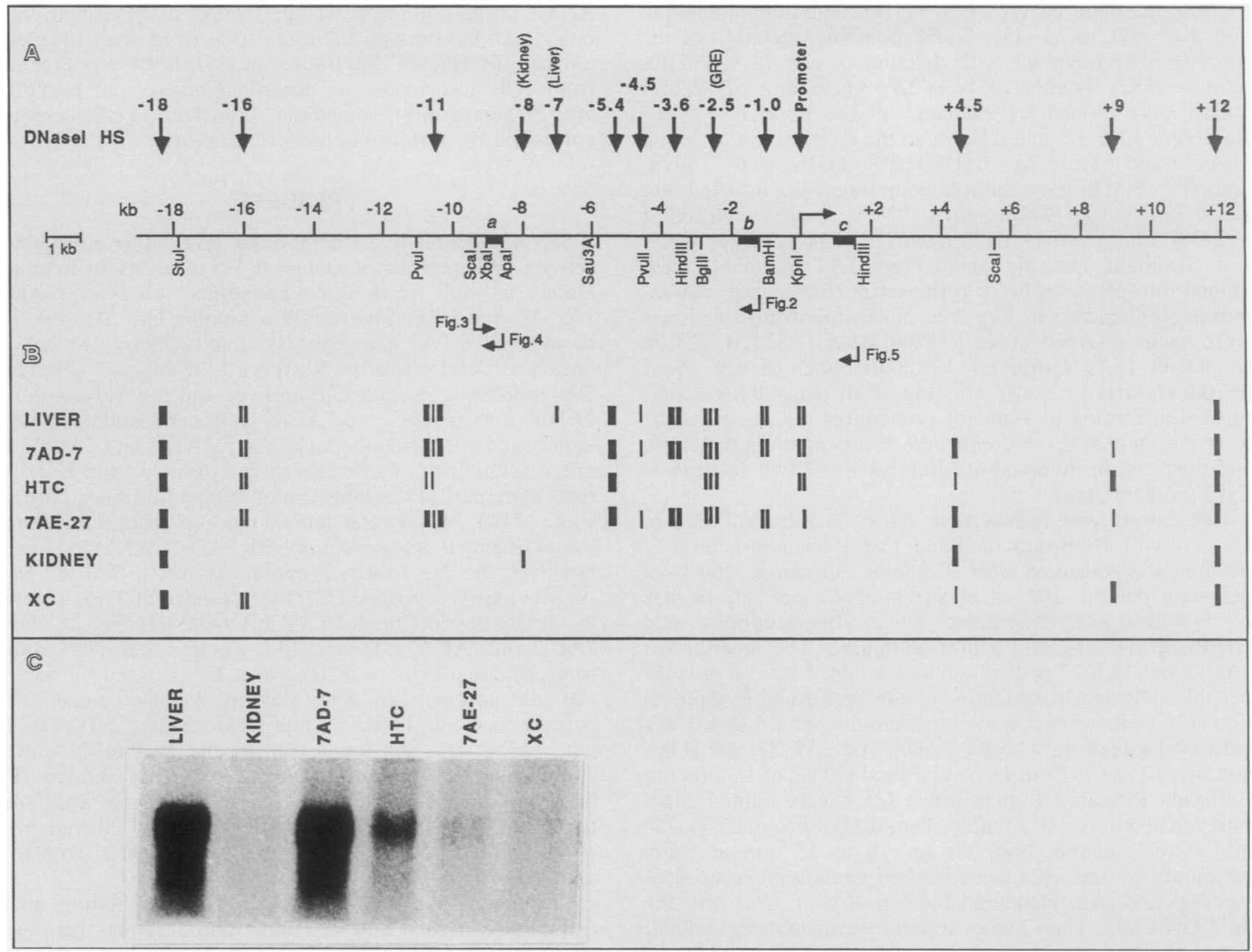

FIG. 1. DNase I HSs in the TAT gene. (A) The rat TAT gene from -19 to $+12 \mathrm{~kb}$ is depicted. The start site and direction of transcription are indicated by an arrow at position 0 . The various DNase I HSs are indicated by vertical arrows at the top of the figure and are named according to their approximate positions relative to the transcription start site. Restriction sites relevant for the analyses of Fig. 2 to 8 are marked. Indirect end-labeling strategies that were used in Fig. 2 to 5 are indicated by arrows below the restriction map; the TAT subclones used as probes are depicted as black boxes: a, XA600; b, EB670; and c, SH800. (B) Summary of the distribution of the various DNase I HSs in different expressing and nonexpressing tissues and cell lines. The occurrence and fine structure of each HS are schematically indicated. (C) Northern analysis of $20 \mu \mathrm{g}$ of total RNA isolated from the indicated tissue or cell line. After electrophoresis, the $1.25 \%$ agarose gel was blotted and hybridized against an SP6 transcript of pSPcTAT3 ${ }^{a}$ (41). Hybridization against pSP64cGAPDH ${ }^{\text {a }}$ (14) was performed to control for RNA loaded (data not shown).

promoter HS, which appear only in liver and a TATexpressing cell line and are therefore candidates as cisregulatory elements.

Differences in chromatin structure of two hepatoma cell lines that express the TAT gene at low levels. From the basal level of TAT mRNA (Fig. 1C) and from the chromatin analysis (Fig. 2), we conclude that 7AD-7 cells best reflect the status of the TAT gene in liver. Since the levels of TAT mRNA are considerably lower in the hepatoma lines HTC and 7AE-27 and absent in XC cells, we examined TAT gene chromatin in these cells to obtain further indications of the relationship of the above-observed HSs to transcriptional activity. These analyses are presented in Fig. 3 to 5, which show HSs from -7 to $+5 \mathrm{~kb}$, from -20 to $-10 \mathrm{~kb}$, and from -3 to $+1 \mathrm{~kb}$, respectively.

In HTC nuclei, only four (-11HS, $-5.4 \mathrm{HS},-2.5 \mathrm{HS}$, and promoter HS) of the seven HSs present in 7AD-7 nuclei between $-11 \mathrm{~kb}$ and the promoter were apparent. Further- more, the $-11 \mathrm{HS}$ had a different substructure in HTC than in 7AD-7 cells (Fig. 4). In contrast, 7AE-27 nuclei displayed an HS pattern identical to that of the Tse-1-negative line, 7AD-7, except for the promoter HS (Fig. 3 and 5). Analysis from a nearby restriction site revealed that the promoter $\mathrm{HS}$ in 7AE-27 cells was not completely absent as appears in Fig. 3 , but the typical doublet seen in liver, 7AD-7, and HTC cells was reduced to the proximal cleavage (Fig. 5 and data not shown). Only HSs at -18 and $-16 \mathrm{~kb}$ were also present in the TAT-nonexpressing fibrosarcoma cell line, XC.

Functional analysis of the TAT $5^{\prime}$-flanking sequences by transient transfection identifies two enhancing elements. Transient transfection of different TAT-CAT fusion constructs was undertaken to establish the relationship between the DNase I HS pattern and transcriptional control regions. A set of $5^{\prime}$ deletion constructs was examined first (Fig. 6A; constructs are named according to the deletion endpoints). In 7AD-7 cells, there were small variations in expression of 


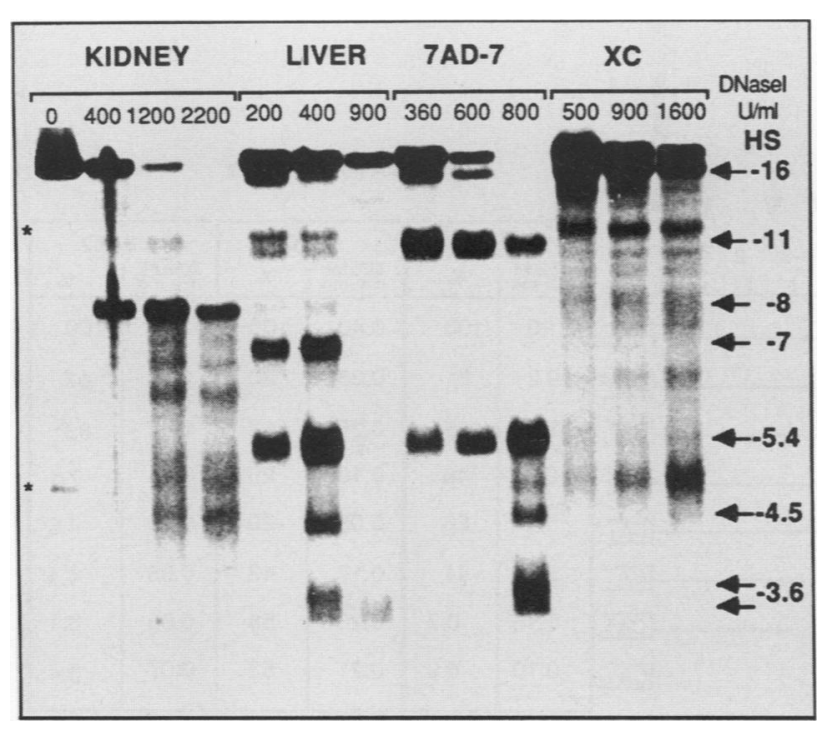

FIG. 2. DNase I HS mapping of the TAT 5'-flanking sequences in liver, kidney, 7AD-7, and XC cells. Nuclei of glucocorticoidinduced liver, kidney, 7AD-7, and XC cells were incubated with increasing amounts of DNase $I$ as indicated. After DNA purification, $20 \mu \mathrm{g}$ of each sample was digested with BamHI, electrophoresed on a $0.8 \%$ agarose gel, blotted, and indirectly end labeled to the BamHI site at -1300 in the TAT gene, using a T3 RNA polymerase transcript of subclone EB670 (Fig. 1A). HSs are indicated by arrows on the right. Artifactual bands are marked by asterisks (compare with Fig. 3 and 4).

plasmids with deletion endpoints from -18.7 to $-4.3 \mathrm{~kb}$. Further deletion to $-3.0 \mathrm{~kb}$, however, led to a $>50$-fold drop in CAT activity. The additionally deleted sequences harbor the $-3.6 \mathrm{HS}$. The 5 ' deletion series was also transfected into HTC and 7AE-27 cells. Consistent with the reduced endogenous TAT mRNA levels in these two cell lines (Fig. 1C),

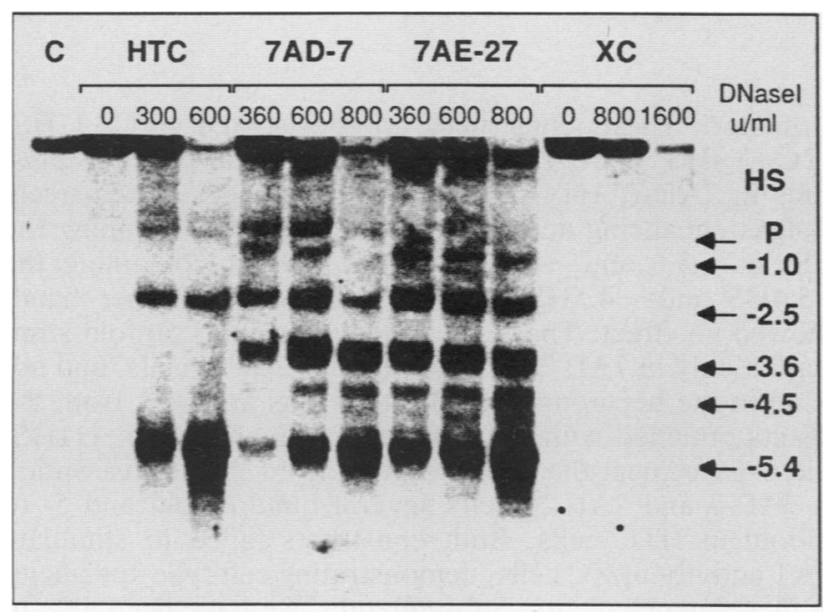

FIG. 3. DNase I HS mapping of the TAT gene region from -8 to $+5 \mathrm{~kb}$. Nuclei of glucocorticoid-induced HTC, 7AD-7, 7AE-27, and XC cells were digested with increasing amounts of DNase I as indicated. After DNA purification, $20 \mu \mathrm{g}$ of each sample was cut with ScaI, electrophoresed in a $0.6 \%$ agarose gel, blotted, and indirectly end labeled to the $S c a I$ site at -9383 in the TAT upstream region, using a T3 RNA polymerase transcript of subclone XA600 (Fig. 1A). Lane C, Protein-free DNA digested with DNase I (50 $\mathrm{U} / \mathrm{ml}$ ). HSs are indicated by arrows on the right. P, Promoter HS.

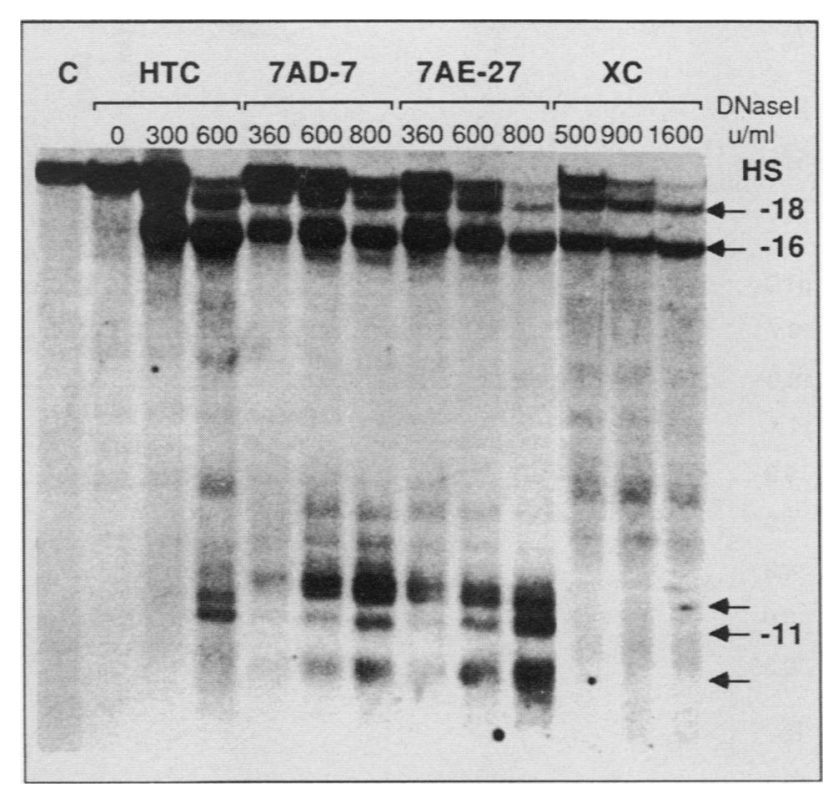

FIG. 4. DNase I HS mapping of the TAT gene region from -22 to $-10 \mathrm{~kb}$. A $20-\mu \mathrm{g}$ sample of each DNA shown in Fig. 3 was cut with ApaI, electrophoresed in a $1 \%$ agarose gel, blotted, and indirectly end labeled to the ApaI site at -8591 in the TAT upstream region, using a T3 RNA polymerase transcript of subclone XA600 (Fig. 1A). Lane C, Protein-free DNA digested with DNase I (50 $\mathrm{U} / \mathrm{ml}$ ). HSs are indicated by arrows on the right.

much lower levels of CAT activity were observed, and deleting the $-3.6 \mathrm{HS}$ had no effect (Fig. 6A). However, in $7 \mathrm{AE}-27$ cells, deletion of sequences between -11 and $-9 \mathrm{~kb}$ led to a $>10$-fold drop in activity (compare pTC11.1 with pTC9.2). A weaker effect (two- to threefold) with the same constructs was also observed in HTC cells.

To verify the results of the $5^{\prime}$ deletion series, plasmids with internal deletions were transfected to look for loss of expression compared with the parental plasmid (Fig. 6B).

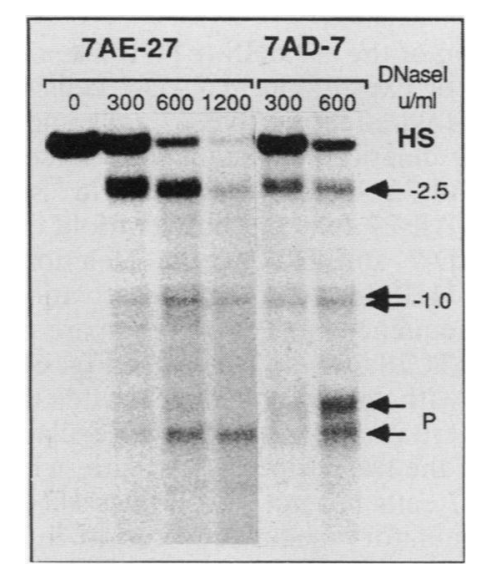

FIG. 5. Chromatin differences at the TAT promoter in 7AD-7 and 7AE-27 cells. Nuclei of glucocorticoid-induced 7AD-7 and 7AE-27 cells were digested with increasing amounts of DNase I as indicated. A 20- $\mu \mathrm{g}$ sample of purified DNA was cut with HindIII, electrophoresed on a $1.25 \%$ agarose gel, blotted, and indirectly end labeled to the HindIII site at +1500 in the TAT-coding sequences, using a T7 transcript of subclone SH800 (Fig. 1A). HSs are indicated by arrows on the right. P, Promoter HS. 


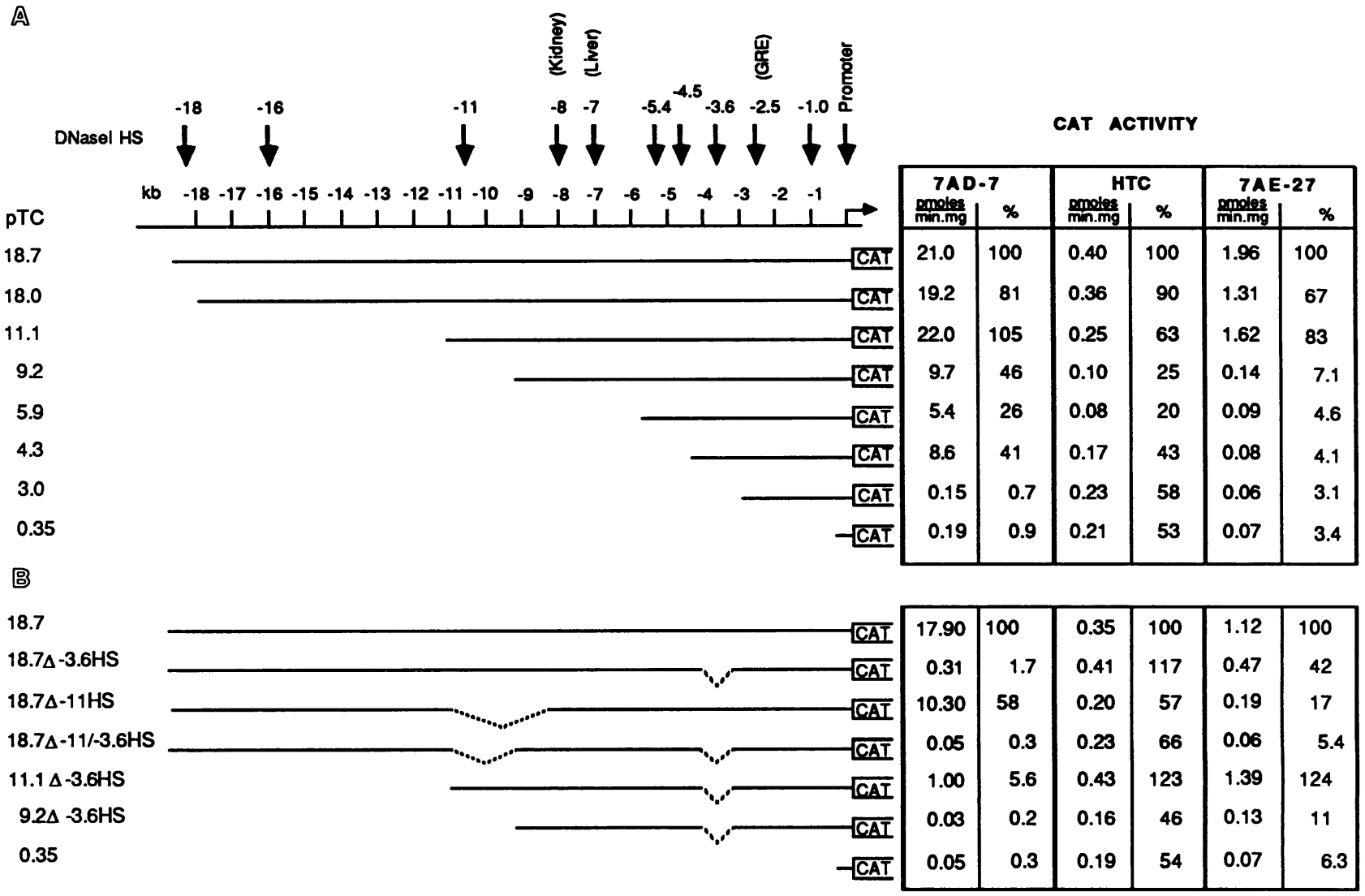

FIG. 6. Transient transfection analyses of the 5 '-flanking region of the TAT gene. Arrows indicate the various DNase I HSs in the TAT $5^{\prime}$-flanking sequences as in Fig. 1. (A) A 5' deletion series as depicted was fused to the CAT gene at position +62 of the rat TAT gene. The 5 ' endpoints of the TAT-CAT fusion constructs (pTC) are given on the left (see Materials and Methods for details). 7AD-7, HTC, and 7AE-27 cells were transfected by lipofection (12). The table on the right presents CAT activities of the respective constructs from a representative experiment. All constructs were tested in at least three independent experiments in each cell line. The absolute activity is given as picomoles of acetylated chloramphenicol per minute per milligram of extract protein, corrected for variation in transfection efficiency by the expression of an internal standard (cotransfected pRSVluc [9]). In addition, expression of the different constructs in each cell line is compared relative to the activity of pTC18.7, which is set at $100 \%$ in that cell line. (B) Series of internal deletions which remove the sequences corresponding to the $-11 \mathrm{HS}$ or $-3.6 \mathrm{HS}$ (see Materials and Methods for details); CAT activities derived from a representative experiment are presented as for panel A.

Internal deletion of the $-3.6 \mathrm{HS}$ (pTC18.7 $-3.6 \mathrm{HS}$ ) led to a dramatic drop of expression in 7AD-7 cells ( $>50$-fold) but had only a twofold effect in 7AE-27 cells and none in HTC cells. Internal deletion of sequences encompassing the -11HS (pTC18.7 $\Delta-11 \mathrm{HS}$ ) resulted in sixfold-reduced expression in 7AE-27 cells but only twofold decreased CAT activity in 7AD-7 and HTC cells. Deletion of both the $-3.6 \mathrm{HS}$ and $-11 \mathrm{HS}$ led to loss of all activation mediated by the upstream sequences analyzed (compare pTC18.7 $1-11$ / $-3.6 \mathrm{HS}$ with pTC18.7 and pTC0.35 in Fig. 6B).

The results with the $5^{\prime}$ and internal deletion constructs showed that there is a critical positive regulatory region 3.6 $\mathrm{kb}$ upstream of the transcription start site, which is strongly active in 7AD-7 cells but not in cell lines HTC and 7AE-27. Additional stimulatory sequences reside in a region that coincides with the -11HS, but in 7AD-7 cells this is obscured by the strong activity correlating with the more proximal $-3.6 \mathrm{HS}$. The effect of the distal element could be clearly documented in 7AD-7 cells if the proximal $-3.6 \mathrm{HS}$

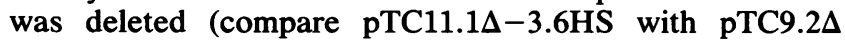
$-3.6 \mathrm{HS}$ in Fig. 6B).

Figure 7 shows results of transfecting plasmids that position individual DNase I HSs in direct proximity to the TAT promoter. These constructs are designated pTC-11HS, pTC-5.4HS, and pTC-3.6HS. Comparison of these plasmids in 7AD-7, HTC, 7AE-27, and XC cells conclusively assigns enhancing activity to the sequences containing the HSs at -3.6 and $-11 \mathrm{~kb}$. The construct containing the $-5.4 \mathrm{HS}$ and $-4.5 \mathrm{HS}$ (pTC-5.4HS), on the other hand, showed no effect. The -3.6 region exerted its 50 -fold stimulation only in 7AD-7 cells, weakly in 7AE-27 cells, and not at all in the hepatoma line HTC, as was apparent from the results obtained with the $5^{\prime}$ deletion mutants. The $-11 \mathrm{HS}$, when placed near the promoter, enhanced TAT transcription in 7AD-7 and 7AE-27 cells several hundredfold and 5- to 10-fold in HTC cells. Both constructs failed to stimulate CAT activity in XC cells, demonstrating cell type specificity of these two elements. Subsequently, we have been able to confine the sequences responsible for transcriptional enhancement entirely to regions within the HSs, and constructs containing these HSs in the reverse orientation produce the same results (data not shown).

Constructs which similarly position the $-18 \mathrm{HS},-16 \mathrm{HS}$, and $-7 \mathrm{HS}$ in front of the TAT promoter failed to reveal any role for these regions in transcriptional regulation in hepatoma and fibroblast cell lines when tested in transient trans- 


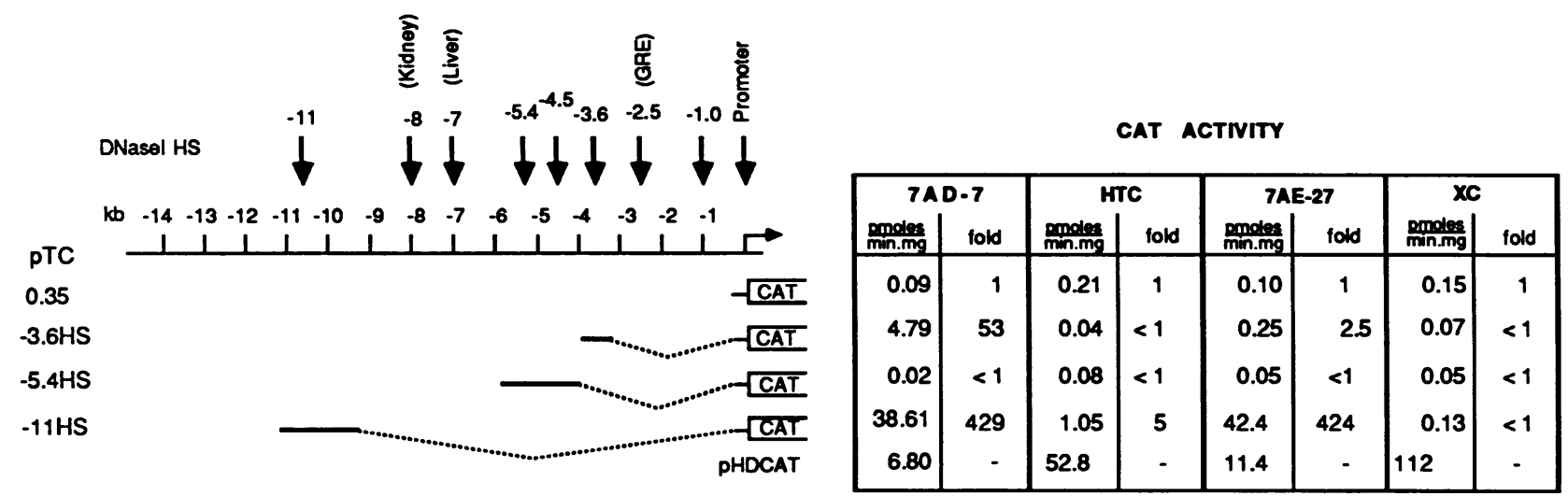

FIG. 7. Correlation of two DNase I HSs upstream of the TAT gene with regions that stimulate the TAT promoter. DNA fragments that encompass individual HSs were cloned in front of the TAT promoter at position -351 base pairs as depicted and introduced into three rat hepatoma cell lines, 7AD-7, HTC, and 7AE-27, and into the rat fibrosarcoma cell line XC. The table on the right presents absolute CAT activities as in Fig. 6 as well as values relative to the parental plasmid (pTC0.35) in each cell line (fold). As a positive control, the cell lines were also transfected with pHDCAT (36), a plasmid that contains the simian virus 40 enhancer driving the thymidine kinase gene promoter.

fections (data not shown). This is also the case with the hepatocyte-specific $\mathrm{HS}$ at $-1.0 \mathrm{~kb}$. The presence of this site, for which in vivo protein binding has been documented (3), does not influence the activity of CAT fusion constructs (compare pTC0.35 and 3.0 in Fig. 6A). Internal deletion of this HS also does not change any property measurable in transient transfections (data not shown). At present, we cannot rule out the possibility that some of the abovementioned HSs must be integrated to convey regulatory function. Also, HSs at the extreme upstream positions (-18HS and $-16 \mathrm{HS})$ could mark features of a neighboring locus of other cell type specificity.

To confirm that the effects measured as CAT activity reflect correct transcriptional regulation at the TAT promoter, RNase protection experiments were performed on RNAs isolated from 7AD-7 cells. Maximal activity of the pTC18.7 construct was lost in two steps (Fig. 8): first, upon deletion of the -11HS (compare pTC11.1 and pTC9.2), and second, upon deletion of the $-3.6 \mathrm{HS}$ (pTC4.3 versus pTC3.0). The activating potential of the distal element compared with that of the proximal element is documented by constructs which position the respective sequences in front of the TAT promoter (pTC-11HS and pTC-3.6HS; compare Fig. 7). In all cases, the correct start site has been used; furthermore, the results qualitatively reflect the effects seen in the CAT assays.

\section{DISCUSSION}

Chromatin and transcriptional control elements of the TAT gene. We have analyzed $\mathbf{4 0} \mathrm{kb}$ of chromatin around the rat TAT gene in different tissues and cell lines for DNase I HSs. HSs at the extreme 5 '- and 3 '-flanking sequences $(-18 \mathrm{HS}$ and $+12 \mathrm{HS}$ ) appear in all analyzed nuclei. Some HSs $(-16 \mathrm{HS},+4.5 \mathrm{HS}$, and +9HS) do not correspond to transcriptional activity or inactivity. On the other hand, a complex array of HSs located between the transcription start site and $11 \mathrm{~kb}$ upstream (-11HS, $-5.4 \mathrm{HS},-4.5 \mathrm{HS}$, $-3.6 \mathrm{HS},-2.5 \mathrm{HS},-1.0 \mathrm{HS}$, and promoter HS) is observed in liver and the TAT-expressing hepatoma line 7AD-7. Interestingly, only three of these HSs $(-5.4 \mathrm{HS},-2.5 \mathrm{HS}$, and promoter HS) are fully established in the hepatoma line HTC, which expresses 5- to 10-fold less TAT mRNA than do 7AD-7 cells. In contrast, 7AE-27, a cell line which shows even lower basal TAT mRNA levels (Fig. 1C) because of the presence of the human Tse-1 locus (34), differs from 7AD-7 cells in DNase I HS pattern only in reduced hypersensitivity at the promoter.

Transient transfection experiments have defined two regions that stimulate TAT transcription, in addition to the glucocorticoid responsive enhancer at $-2.5 \mathrm{~kb}$ previously described (31). These two enhancers lie far upstream of the promoter and coincide with the $-3.6 \mathrm{HS}$ and $-11 \mathrm{HS}$. Both elements act in a hepatoma-specific manner; however, the activity of the -3.6 enhancer is restricted to the H4IIEC3derived cell line 7AD-7. It is not active in HTC cells, which do not show the corresponding HS. The -3.6 enhancer also contains a cAMP response element of the TAT gene, which not only mediates cAMP responsiveness but also functions to raise the basal level of TAT transcription (Weih et al., submitted). We conclude that in HTC cells, the lower basal level of TAT transcription as well as the absence of a transcriptional response to cAMP alone (22) is in part due to the inactivity of the enhancer that creates this HS. In 7AE-27 cells the -3.6 enhancer activity is greatly reduced, but the corresponding $\mathrm{HS}$ is as strong as that which lies over the active enhancer in 7AD-7 cells. A detailed analysis of this enhancer and the basis of its inactivity in 7AE-27 cells will be presented elsewhere (M. Boshart, F. Weih, A. Schmidt, R. E. K. Fournier, and G. Schütz, Cell, in press).

The TAT gene has a second far upstream enhancer $(-11 \mathrm{HS})$ whose activity in CAT assays is obscured by the strong effect of the more proximal -3.6HS when both elements are active. Constructs which juxtapose the respective sequences to the TAT promoter establish that the upstream enhancer is the stronger of the two (Fig. 7 and 8). Possibly transient transfection experiments are inadequate to describe fully the in vivo function of the distal element. In the $\alpha$-fetoprotein gene, three enhancers, located 2.5, 5.0, and $6.5 \mathrm{~kb}$ upstream, were shown to be functionally equivalent and nonadditive in transient transfections $(16,17)$. Transgenic mice and chromatin analysis, however, defined variations between tissues in the utilization of the three enhancers $(18,27)$. Redundance of transcriptional enhancers might also reflect a sequential activation during development. The dominant control region (DCR) of the $\beta$-globin gene cluster may function to establish the character of this domain, since 


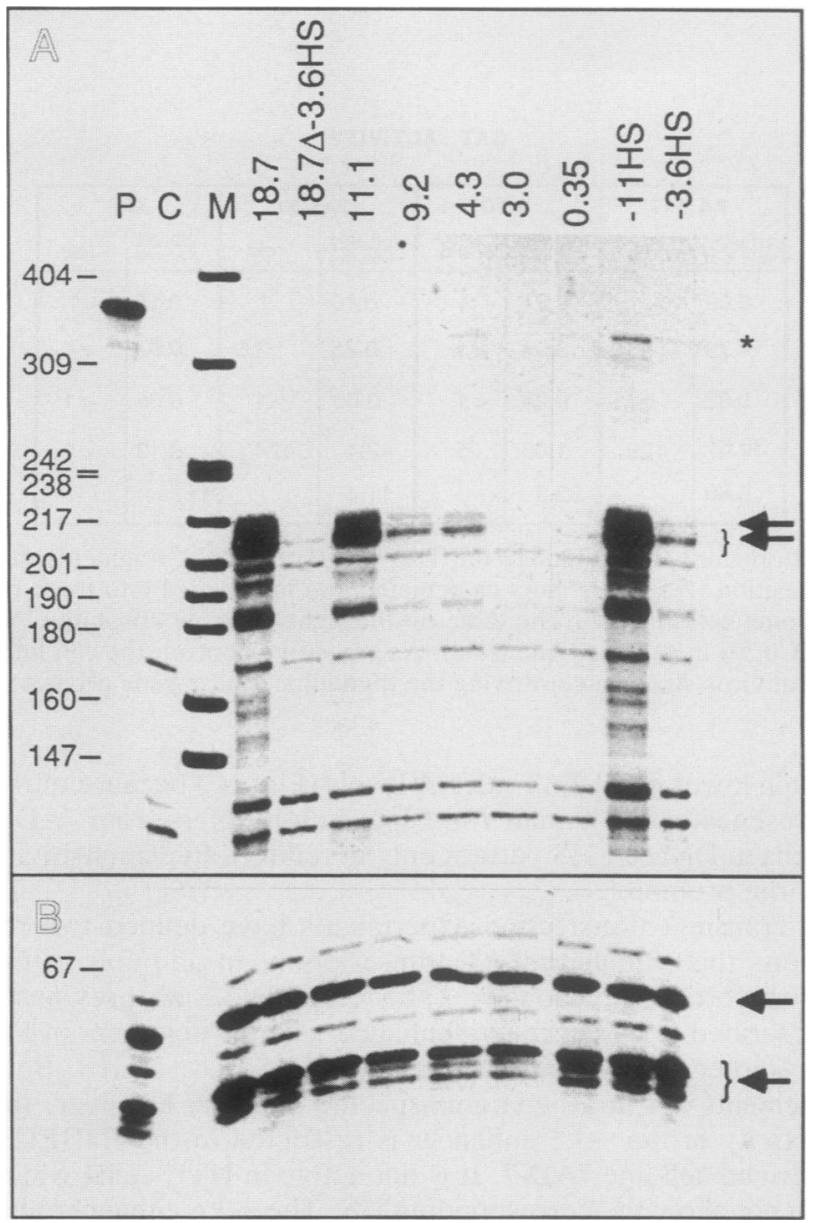

FIG. 8. The TAT enhancers stimulate transcription at the correct start sites. 7AD-7 cells were transfected with pTC constructs as indicated at the top. Total RNA was prepared; $100 \mu \mathrm{g}$ was hybridized to a uniformly labeled antisense SP6 transcript of subclone pSpTATCAT (31) and digested with RNase. Protected fragments were separated on a $6 \%$ sequencing gel. The TAT gene displays microheterogeneity at its start site; correctly initiated transcripts are indicated by arrows and braces on both panels. Upstream starts are marked by an asterisk. Lane $P$, undigested probe; lane C, RNA from untransfected 7AD-7 cells; lane M, HpaII-digested, end-labeled pBR322. Fragment sizes in base pairs are indicated on the left. (B) Shorter exposure of the lower half of the gel to observe transcripts originating from the endogenous TAT gene, which served as an internal control.

the HSs that mark the DCR appear before $\beta$-globin transcription in minilocus reconstructions (49) and the DCR conveys independence from position effects in transgenic mice (26). For the TAT gene, the distal element (-11HS) could function early in development to establish an activated locus in which regulated gene expression is then conferred by the other cis-regulatory elements. Preliminary HS observations made on the TAT gene in fetal livers support this hypothesis.

Although the promoters of many other liver genes strongly stimulate transcriptional activity $(6,8,16,17,20,30,37)$, we observed that the TAT promoter is relatively weak in the absence of its upstream elements. Nevertheless, the observation that the presence of Tse-1 alters the promoter-HS (Fig. 5) may suggest a role for the promoter in transcriptional control of the TAT gene.

Functional relevance of the different chromatin states of the
TABLE 1. Summary of TAT enhancer activities as analyzed by transient transfection, the structure of corresponding DNase I HSs, and TAT mRNA levels in different cell lines

\begin{tabular}{|c|c|c|c|c|c|c|c|c|}
\hline cell line & activity & 11 & & $\begin{array}{l}3.6 \\
\text { HS }\end{array}$ & \begin{tabular}{|r|}
-2.5 \\
inducibility
\end{tabular} & & \begin{tabular}{|l|}
$\mathbf{P}^{\mathbf{b}}$ \\
HS
\end{tabular} & $\begin{array}{l}\text { basal } \\
\text { TAT } \\
\text { mRNA } \\
\text { lovels }\end{array}$ \\
\hline 7AD-7 & +++++4 & & ++++ & & $+\quad c$ & & II & high \\
\hline HTC & + & \| & - & absent & + & & & low \\
\hline 7AE-27 & +++++ & & $(-)$ & II & + & & & very low \\
\hline$x c$ & - & absent & - & absem & + & absem & absont & $\begin{array}{l}\text { un- } \\
\text { dotectable }\end{array}$ \\
\hline
\end{tabular}

${ }^{a}$ Inducibility of the -2.5 enhancer and HS by glucocorticoids.

${ }^{b}$ Promoter.

${ }^{c}$ Data not shown.

TAT gene. By contrasting enhancer activity in transient transfection assays with the occurrence and structure of the corresponding HSs in four cell lines (Table 1), a descriptive understanding of the transcriptionally active TAT gene is now possible. In the highly differentiated hepatoma cell line 7AD-7, both -11 and -3.6 enhancers are active and display strong HSs in chromatin. The promoter HS is strong, and high levels of TAT mRNA are produced. Transcriptional activity can be stimulated by either glucocorticoids, which induce the -2.5 enhancer and HS, or cAMP, whose effect is mediated by a cAMP response element resident in the -3.6HS (Table 1; Weih et al., submitted).

In another hepatoma cell line, HTC, the -11 enhancer activity and corresponding HS are weaker than in 7AD-7 cells. The -3.6 enhancer activity and HS are absent. The reduced activity of these two enhancers correlates to lower levels of endogenous TAT mRNA. The promoter-HS is strong, and the transcriptional activity of the gene can be stimulated by glucocorticoids through the inducible enhancer and HS at $-2.5 \mathrm{~kb}$.

In the Tse-1-containing cell line 7AE-27, the -11 enhancer activity and $\mathrm{HS}$ are both strong. Although the -3.6 enhancer is almost completely inactive, its corresponding HS is fully established. By comparison with HTC cells, it can be seen that both of these enhancers are more active in 7AE-27 cells, although TAT mRNA levels are lower (Table 1). This incongruency suggests that the promoter has functional relevance, since in 7AE-27 cells, hypersensitivity is altered only at the promoter. The reduced promoter HS may be a result of direct action by Tse-1. Alternatively, it may be a consequence of $T s e-1$-induced alterations of the -3.6 enhancer. The following observation might also indicate a role of promoter sequences in TAT gene control in 7AE-27 cells. In transient transfection experiments, the -2.5 enhancer responds to glucocorticoids. However, transcriptional stimulation of the endogenous gene is impaired, even though the HS is inducible (32; data not shown). Experiments to establish whether Tse-1 exerts an effect on the TAT gene in HTC cells, in which the $-3.6 \mathrm{HS}$ is not present, would resolve this issue.

In XC cells, both the -11 and -3.6 enhancers are inactive and the corresponding HSs are absent. The -2.5HS is not inducible with glucocorticoids, but the corresponding enhancer activity is partially inducible. This finding indicates the presence of the glucocorticoid receptor in XC cells and its ability to activate the -2.5 enhancer when the latter is transfected but not in chromatin. 
Correlation between a DNase I HS and enhancer activity. In addition to the chromatin-guided definition of two transcriptional enhancers in the rat TAT gene, this study documents other DNase I HSs which also appear exclusively in expressing cell lines and liver but so far could not be correlated with function $(-5.4 \mathrm{HS},-4.5 \mathrm{HS}$, and $1.0 \mathrm{HS})$. After completion of this report, we became aware of a recent report by Grange et al. (21). The authors suggest a functional role for the $-5.4 \mathrm{HS}$ in steroid hormone response in H4IIEC3 cells. After transfection of similar constructs and induction in the two hepatoma cell lines FTO-2B and HTC, we cannot confirm these observations (data not shown).

For the $-1.0 \mathrm{HS}$, in vivo protein-DNA interaction, hypomethylation in cells in which the gene is transcribed, and in vivo topoisomerase I activity have been documented $(3,45)$. So far, no function for this DNase I HS has been found. Furthermore, although we observe a correlation between enhancer activity and the structure of the -11HS, we also find, with the $-3.6 \mathrm{HS}$, a situation where hypersensitivity over an enhancer does not correlate to the activity of the enhancer. These findings lead us to draw the following unidirectional conclusion. cis elements that regulate celltype-specific gene transcription lie within DNase I HSs. However, the occurrence of a cell-type-specific DNase I HS does not imply the existence of cis-regulatory elements active in transient transfection assays.

\section{ACKNOWLEDGMENTS}

We are grateful to R. J. Leach and R. E. K. Fournier for providing the cell lines 7AD-7 and 7AE-27 and to A. Hecht for the gift of plasmid pRSVlucAH. We thank R. Hipskind, G. Kelsey, M. Nichols, P. Shaw, and U. Strähle for critical comments on the manuscript, C. Schneider for secretarial assistance, and S. Mähler and $\mathrm{W}$. Fleischer for photography.

This work was supported by the Deutsche Forschungsgemeinschaft and the Fonds der Chemischen Industrie.

\section{LITERATURE CITED}

1. Ausubel, F. M., R. Brent, R. E. Kingston, D. D. Moore, J. G. Seidman, J. A. Smith, and K. Struhl. 1988. Current protocols in molecular biology. John Wiley \& Sons, Inc., New York.

2. Becker, P. B., R. Renkawitz, and G. Schütz. 1984. Tissuespecific DNaseI hypersensitive sites in the 5 '-flanking sequences of the tryptophan oxygenase and the tyrosine aminotransferase genes. EMBO J. 3:2015-2020.

3. Becker, P. B., S. Ruppert, and G. Schütz. 1987. Genomic footprinting reveals cell type-specific DNA binding of ubiquitous factors. Cell 51:435-443.

4. Bradford, M. 1976. A rapid and sensitive method for the quantitation of microgram quantities of protein utilizing the principle of protein-dye binding. Anal. Biochem. 72:248-254.

5. Cathala, G., J.-F. Savouret, B. Mendez, B. L. West, M. Karin, J. A. Martial, and J. D. Baxter. 1983. A method for isolation of intact, translationally active ribonucleic acid. DNA 2:329-335.

6. Costa, R. H., L. Eseng, and J. E. Darnell. 1986. Transcriptional control of the mouse prealbumin (transthyretin) gene: both promoter sequences and a distinct enhancer are cell specific. Mol. Cell. Biol. 6:4697-4708.

7. Crabb, D. W., and J. E. Dixon. 1987. A method for increasing the sensitivity of chloramphenicol acetyltransferase assays in extracts of transfected cultured cells. Anal. Biochem. 163: 88-92.

8. De Simone, V., G. Cileberto, E. Hardon, G. Paonessa, F. Palla, L. Lundberg, and R. Cortese. 1987. Cis- and trans-acting elements responsible for the cell type specific expression of the human $\alpha 1$-antitrypsin gene. EMBO J. 6:2759-2766.

9. de Wet, J. R., K. V. Wood, M. DeLuca, D. R. Helinski, and S. Subramani. 1987. Firefly luciferase gene: structure and expression in mammalian cells. Mol. Cell. Biol. 7:725-737.
10. Dobner, E., E. S. Kawasaki, L.-Y. Yu, and C. Bancroft. 1981. Thyroid or glucocorticoid hormone induces pre-growth-hormone mRNA and its probable precursor in rat pituitary cells. Proc. Natl. Acad. Sci. USA 78:2230-2234.

11. Elgin, S. C. R. 1988. The formation and function of DNase $I$ hypersensitive sites in the process of gene activation. J. Biol. Chem. 263:19259-19262.

12. Felgner, P. L., T. R. Gadek, M. Holm, R. Roman, H. W. Chan, M. Wenz, J. P. Northrup, G. M. Ringold, and M. Danielsen. 1987. Lipofection: a highly efficient, lipid-mediated DNA-transfection procedure. Proc. Natl. Acad. Sci. USA 84:7413-7417.

13. Forrester, W. C., S. Takegawa, T. Papayannopoulou, G. Stamatoyannopoulos, and M. Groudine. 1987. Evidence for a locus activating region: the formation of developmentally stable hypersensitive sites in globin expressing hybrids. Nucleic Acids Res.. 15:10159-10177.

14. Fort, P., L. Marty, M. Piechaczyk, S. El Sabrouty, C. Dani, P. Jeanteur, and J. M. Blanchard. 1985. Various rat adult tissues express only one major mRNA species from the glyceraldehyde-3-phosphate dehydrogenase multigenic family. Nucleic Acids Res. 13:1431-1442.

15. Fritton, H. P., T. Igo-Kemenes, J. Nowock, U. Strech-Jurk, M. Theisen, and A. E. Sippel. 1987. DNaseI-hypersensitive sites in the chromatin structure of the lysozyme gene in steroid hormone target and non-target cells. Biol. Chem. Hoppe-Seyler 368:111-119.

16. Godbout, R., R. Ingram, and S. M. Tilghman. 1986. Multiple regulatory elements in the intergenic region between the $\alpha$ fetoprotein and albumin genes. Mol. Cell. Biol. 6:477-487.

17. Godbout, R., R. Ingram, and S. M. Tilghman. 1988. Finestructure mapping of the three mouse $\alpha$-fetoprotein gene enhancers. Mol. Cell. Biol. 8:1169-1178.

18. Godbout, R., and S. M. Tilghman. 1988. Configuration of the $\alpha$-fetoprotein regulatory domain during development. Genes Dev. 2:949-956.

19. Gorman, C. M., L. F. Moffat, and B. H. Howard. 1982. Recombinant genomes which express chloramphenicol acetyltransferase in mammalian cells. Mol. Cell. Biol. 2:1044-1051.

20. Gorski, K., M. Carneiro, and U. Schibler. 1986. Tissue-specific in vitro transcription from mouse albumin promoter. Cell 47: 767-776.

21. Grange, T., J. Roux, and R. Pietet. 1989. Two remote glucocorticoid responsive units interact cooperatively to promote glucocorticoid induction of rat tyrosine aminotransferase gene expression. Nucleic Acids Res. 17:8695-8709.

22. Granner, D. K. 1976. Restoration of sensitivity of cultured hepatoma cells to cyclic nucleotides shows permissive effect of dexamethasone. Nature (London) 259:572-573.

23. Granner, D. K., and E. G. Beale. 1985. Regulation of the synthesis of tyrosine aminotransferase and phosphoenolpyruvate carboxykinase by glucocorticoid hormones, p. 89-138. In G. Litwack (ed.), Biochemical actions of hormones XII. Academic Press, Inc., New York.

24. Greengard, O. 1970. The developmental formation of enzymes in rat liver, p. 53-85. In G. Litwack (ed.), Mechanism of hormone action I. Academic Press, Inc., New York.

25. Gross, D. S., and W. T. Garrard. 1988. Nuclease hypersensitive sites in chromatin. Annu. Rev. Biochem. 57:159-197.

26. Grosveld, F., G. B. van Assendelft, D. R. Greaves, and G. Kollias. 1987. Position-independent, high-level expression of the human $\beta$-globin in transgenic mice. Cell 51:975-985.

27. Hammer, R. E., R. Krumlauf, S. A. Camper, R. L. Brinster, and S. M. Tilghman. 1987. Diversity of alpha-fetoprotein gene expression in mice is generated by a combination of separate enhancer elements. Science 235:53-58.

28. Hargrove, J. L., and D. K. Granner. 1985. Biosynthesis and intracellular processing of tyrosine aminotransferase, p. 511532. In P. Christen and P. E. Metzler (ed.), Transaminases. John Wiley \& Sons, Inc., New York.

29. Hashimoto, S., W. Schmid, and G. Schütz. 1984. Transcriptional activation of the rat liver tyrosine aminotransferase gene by cAMP. Proc. Natl. Acad. Sci. USA 81:6637-6641.

30. Heard, J.-M., P. Herbomel, M.-O. Ott, A. Mottura-Roller, 
M. C. Weiss, and M. Yaniv. 1987. Determinants of rat albumin promoter tissue specificity analysed by an improved transient expression system. Mol. Cell. Biol. 7:2425-2434.

31. Jantzen, H. M., U. Strähle, B. Gloss, F. Stewart, W. Schmid, M. Boshart, R. Miksicek, and G. Schütz. 1987. Cooperativity of glucocorticoid response elements located far upstream of the tyrosine aminotransferase gene. Cell 49:29-38.

32. Killary, A. M., and R. E. K. Fournier. 1984. A genetic analysis of extinction: trans-dominant loci regulate expression of liverspecific traits in hepatoma hybrid cells. Cell 38:523-534.

33. Leach, R. J., M. J. Thayer, A. J. Schafer, and R. E. K. Fournier. 1989. Physical mapping of human chromosome 17 using fragment-containing microcell hybrids. Genomics 5:167-176.

34. Lem, J., A. C. Chin, M. J. Thayer, R. J. Leach, and R. E. K. Fournier. 1988. Coordinate regulation of two genes encoding gluconeogenic enzymes by the trans-dominant locus Tse-1. Proc. Natl. Acad. Sci. USA 85:7302-7306.

35. Melton, D. A., P. A. Krieg, M. R. Rebagliati, T. Maniatis, K. Zinn, and M. R. Green. 1984. Efficient in vitro synthesis of biologically active RNA and RNA-hybridisation probes from plasmids containing a bacteriophage SP6 promoter. Nucleic Acids Res. 12:7035-7056.

36. Müller, G., S. Ruppert, E. Schmid, and G. Schütz. 1988. Functional analysis of alternatively spliced tyrosinase gene transcripts. EMBO J. 7:2723-2730.

37. Oliviero, S., G. Morrone, and R. Cortese. 1987. The human haptoglobin gene: transcriptional regulation during development and acute phase induction. EMBO J. 6:1905-1912.

38. Ott, M.-O., L. Sperling, P. Herbomel, M. Yaniv, and M. C. Weiss. 1984. Tissue-specific expression is conferred by a sequence from the $5^{\prime}$ end of the rat albumin gene. EMBO J. 3:2505-2510.

39. Pinkert, C. A., D. M. Ornitz, R. L. Brinster, and R. D. Palmiter. 1987. An albumin enhancer located $10 \mathrm{~kb}$ upstream functions along with its promoter to direct efficient, liver-specific expression in transgenic mice. Genes Dev. 1:268-276.
40. Ruiz-Bravo, N., and M. J. Ernest. 1982. Induction of tyrosine aminotransferase mRNA by glucocorticoids and cAMP in fetal rat liver. Proc. Natl. Acad. Sci. USA 79:365-368.

41. Scherer, G., W. Schmid, C. M. Strange, W. Röwekamp, and G. Schütz. 1982. Isolation of cDNA clones coding for rat tyrosine aminotransferase. Proc. Natl. Acad. Sci. USA 79:7205-7208.

42. Schmid, E., W. Schmid, D. Mayer, B. Jastorff, and G. Schütz. 1987. Transcriptional activation of the tyrosine aminotransferase gene by glucocorticoids and cAMP in primary hepatocytes. Eur. J. Biochem. 165:499-506.

43. Schneider, J. A., and M. C. Weiss. 1971. Expression of differentiated functions in hepatoma cell hybrids. I. Tyrosine aminotransferase in hepatoma-fibroblast hybrids. Proc. Natl. Acad. Sci. USA 68:127-131.

44. Shinomiya, T., G. Scherer, W. Schmid, H. Zentgraf, and G. Schütz. 1984. Isolation and characterization of the rat tyrosine aminotransferase gene. Proc. Natl. Acad. Sci. USA 81:13461350.

45. Stewart, A. F., and G. Schütz. 1987. Camptothecin-induced in vivo topoisomerase I cleavages in the transcriptionally active tyrosine aminotransferase gene. Cell 50:1109-1117.

46. Svoboda, J. 1960. Presence of chicken tumor virus in the sarcoma of the adult rat inoculated after birth with Rous sarcoma virus. Nature (London) 186:980-981.

47. Thompson, E. B., G. M. Tomkins, and J. F. Curran. 1966 Induction of tyrosine $\alpha$-ketoglutarate transaminase by steroid hormones in a newly established tissue culture cell line. Proc. Natl. Acad. Sci. USA 56:296-303.

48. Tuan, D., W. Solomon, Q. $\mathbf{L i}$, and I. M. London. 1985. The " $\beta$-like-globin" gene domain in human erythroid cells. Proc. Natl. Acad. Sci. USA 82:6384-6388.

49. van Assendelft, G. B., O. Hanscombe, F. Grosveld, and D. R. Greaves. 1989. The $\beta$-globin dominant control region activates homologous and heterologous promoters in a tissue-specific manner. Cell 56:969-977. 